\title{
Transepistemologías inclusivas en la Educación Matemática Decolonial Transcompleja
}

Resumen: La inclusión es esgrimida como bandera colonial en la modernidad, está profundamente excluyente. Con la deconstrucción rizomática como transmétodo se cumple con el objetivo complejo de: analizar transepistemologías inclusivas en la Educación Matemática Decolonial Transcompleja. En la reconstrucción se prenden inclusiones en las transepistemologías ecosóficas-antropoéticas ricas en la esencia compleja y transdisciplinar de la Matemática, que conlleva a diálogos dialógicosdialécticos para provocar la conciencia de nuestro accionar en el mundo, las necesidades de identidad tanto individual como planetaria, las necesidades educativas especiales; conviviendo desde el amor por nuestra creación con conocimiento matemáticos pertinentes. Estas transepistemologías anidan una educación inclusiva ecosófica de la Matemática; que atiende una responsabilidad social imprimida de la necesidad de liberación de los olvidados. Estas transepistemologías se van reconstruyendo en el calor decolonial, el entusiasmo por aprender, con una profunda fe en el educando; su potencial y sensibilidad que necesitan ser provocada.

Palabra clave: Transepistemologías. Inclusión. Re-ligaje. Educación Matemática Decolonial Transcompleja.

\section{Inclusive transpistemologies in Transcomplex Decolonial Mathematics Education}

Abstract: Inclusion is brandished as a colonial flag in modernity, it is deeply exclusive. With rhizomatic deconstruction as a transmethod, the complex objective of analyzing inclusive transepistemologies in Transcomplex Decolonial Mathematical Education is fulfilled. In the reconstruction inclusions are caught in the ecosophic-anthropoetic transepistemologies rich in the complex and transdisciplinary essence of mathematics, which leads to dialogic-dialectical dialogues to provoke awareness of our actions in the world, the needs of both individual and planetary identity, special educational needs; coexisting from the love for our creation with pertinent mathematical knowledge. These transepistemologies nest an inclusive ecosophic education of Mathematics; that serves a social responsibility based on the need to liberate the forgotten. These transepistemologies are being rebuilt in the decolonial warmth, the enthusiasm for learning, with a deep faith in the learner; its potential and sensitivity that need to be provoked.

Keywords: Transepistemologies. Inclusion. Re-linking. Decolonial Transcomplex Mathematical Education.

\section{Transpistemologias Inclusivas na Educação Matemática Decolonial Transcomplexa}


Resumo: A inclusão é brandida como uma bandeira colonial na modernidade, é profundamente exclusiva. Com a desconstrução rizomática como um transmétodo, o complexo objetivo de analisar transepistemologias inclusivas na Educação Matemática Decolonial Transcomplexa é cumprido. Na reconstrução, as inclusões são captadas nas transepistemologias ecosóficas-antropoéticas, ricas na essência complexa e transdisciplinar da Matemática, que conduzem a diálogos dialógico-dialéticos para provocar a consciência de nossas ações no mundo, das necessidades da identidade individual e planetária, necessidades educacionais especiais; coexistindo do amor pela nossa criação com conhecimentos matemáticos pertinentes. Essas transepistemologias aninham uma educação ecossófica inclusiva de Matemática; que cumpre uma responsabilidade social baseada na necessidade de libertar os esquecidos. Essas transepistemologias vão sendo reconstruídas no calor decolonial, no entusiasmo pelo aprendizado, com uma fé profunda no aprendiz; seu potencial e sensibilidade que precisam ser provocados.

Palavras-chave: Transepistemologias. Inclusão. Religando. Educação Matemática Decolonial Transcomplexa.

La Educación Matemática hoy se encuentra en el proyecto modernista, caracterizado de una exclusión generalizada, así que hablar de la educación modernista incluyente es una paradoja (RODRÍGUEZ, 2020a).

\section{Rizoma transmetodológico. ¿Qué son las transepistemologías? EI transmétodo de investigación y motivaciones iniciales}

Internalizando las palabras del epígrafe que aluden al tema de investigación conseguimos con el término paradoja una figura de pensamiento que consiste en aprovechar locuciones que aparentemente envuelven negaciones; entonces esperar inclusión en la Educación Modernista ciertamente es una paradoja. Iremos desmitificando las categorías; y adelantamos que la manera de hacerlo no está imbricada en las investigaciones tradicionales del paradigma dominante colonial; no queremos paradojas en medio de una palabra tan resaltante y a la vez tan usada a criterio de conveniencia como lo es: inclusión; ciertamente digna convocatoria a la que acudimos en plena era tecnológica donde la inclusión en general en la educación es profundamente excluyente (RODRÍGUEZ, 2020a).

Si pensáramos en la paradoja que mucho tiempo ha deleitado a los lectores de Pablo Neruda, en su obra: Un soneto de amor; recordaríamos esa figura en las paradojas literarias que dice "yo te amo para comenzar a amarte, para recomenzar el infinito y para no dejar de amarte nunca: por eso no te amo todavía" (NERUDA, 1959, p. 23). Así retomando la conexión con la educación hoy, particularmente con la enunciación occidental: la Educación Matemática para todos esta tiene la mayor exclusión que 
contradice dicho lema. Mostraremos nuestras afirmaciones en consonancia con categorías como: Educación Matemática Decolonial Transcompleja (EMDT) (RODRÍGUEZ, 2020b), transepistemologías, inclusión, ecosofía, antropoética, rizoma, re-ligar (RODRÍGUEZ, 2019a) entre otras posibles de su inclusión en el transparadigma transcomplejo y el proyecto decolonial planetario: la transmodernidad. En consonancia con el transmétodo: la deconstrucción rizomática (RODRÍGUEZ, 2019b).

La Educación Matemática Decolonial Transcompleja (EMDT) como línea de investigación compleja y transdisciplinar es inclusiva, desde luego de perspectivas de la Etnomatemática, la Educación Matemática Critica; pero ella atiende a el dialogo de saberes y la minimización de los saberes matemáticos científicos y los mal denominados soterrados; se trata de la construcción de un nuevo marco teórico de Educación Matemática, que no tiene parcela, y no atiende a apellidos de la Matemática en tanto Matemática occidental, atiende al principio máximo que la Matemática es legado de la humanidad, y en ellas tiene tanta preeminencia la creada en el Norte como en el Sur, la de las civilizaciones execradas como las de otras civilizaciones.

En cuanto al sujeto investigador y sus subjetividades ellas están incluidas, presentes con voz activa, son preeminencias de los transmétodos. Ello puede crear un rechazo en lo instituido como verdad objetiva, la autora no busca verdad definitiva, no cree en esa posibilidad como imposición y religa su hacer en cada rizoma de la indagación, se solicita respetuosamente advertir que se trata de nuevas transepistemologías inclusivas, atenientes al respeto de la condición humana y subjetividades. También convergen muchos investigadores en una transdisciplinariedad y confluencias de aportes.

Todo ello, para analizar transepistemologías inclusivas en la Educación Matemática Decolonial Transcompleja como objetivo complejo de investigación. Es urgente ya saber que: ¿Qué son las transepistemologías? La semántica de transepistemologías va más allá de las epistemologías tradicionales; ¿Qué significa la transepistemologías? la noción de las transepistemologías, “como campo epistémico que soportaría la investigación transcompleja como un enfoque que va más allá de la explicación e interpretación (...) es una postura que aboga por un sentido incluyente, convivencial y holístico del conocimiento" (SCHAVINO, 2013, p. 75). 
Con las transepistemologías se consigue la posibilidad de "borrosidad de las investigaciones; es ir a otros estadios del pensamiento, entendiendo la resignificación de las ciencias como una necesidad de revisión" (RODRÍGUEZ, 2019a, p. 30); pues los fenómenos son versátiles incluidos en realidades fractálicas no regularizables, y en ningún tiempo lineales; las matemáticas de la complejidad son ejemplos de la reformulación y avance complejo de la matemáticas; así se espera el cambio en su educación; se trata de superar la disyunción positivista e interpretativa de la modernidadpostmodernidad-colonialidad.

Van las transepistemologías en consonancia con al grado de conciencia de que en la búsqueda de saberes matemáticos "se encuentran necesidades propias de una sociedad cambiante, la realidad, la incertidumbre, lo imaginario, el arte, la expresión del ser y su entorno definen una visión planetaria que permite la producción del conocimiento buscado" (SORET, 2016, p. 37). Para cubrir esas necesidades e intentar incluirlas siempre como posibilidades de mejoras hacen falta un re-ligar como urgencia de la transmodernidad (RODRIGUEZ, 2019a), se trata de des-ligarse de los viejos patrones soslayadores de hacer Educación Matemática e ir a la decolonialidad planetaria como posibilidad de convivir los saberes científicos y los mal llamados soterrados de la matemática re-ligándolos; la convivencia de la visiones científicas y la de las subjetividades de los actores del proceso educativo. Ello irá, como lo veremos más adelante, con la matemática occidental más allá, anidándola y complejizándola; sin apellidos excluyentes.

Es así como, la transcomplejidad, conjunción compleja y transdisciplinar que es profundamente inclusiva; pero que los rezagos coloniales han llevado a consideraciones transdisciplinares en el cono de la modernidad: la postmodernidad (DUSSEL, 1992); con ello no toda transdisciplinariedad de la manera que se viene llevando a la práctica es decolonial, "la descolonización epistémica envuelve variadas formas de transdisciplinariedad pero no todas las formas de transdisciplinariedad son decoloniales" (MALDONADO-TORRES, 2015, p. 2). Explicitaremos más adelante que ha pasado especialmente en la Educación Matemática.

En, así como, la decolonialidad planetaria es inclusiva, no hay un Norte sin un Sur, pero tampoco un Sur sin un Norte, "es imperativo recordar que esta genealogía es 
planetaria, que el pensamiento decolonial se asienta e incorpora en movimientos sociales; no se limita a individuos" (RINCÓN, MILLÁN y RINCÓN, 2015, p.80). Nos desprendemos de la tiranía en cualquier sentido; declaramos la inclusión como una categoría decolonial, que la definiéremos más adelante y entrelazamos con la EMDT.

Definimos inclusión en planos complejos, sin restricciones o parcelas en ciencias o saberes; sino con todos; inclusión es "un poderoso mecanismo de reconfiguración del mundo contemporáneo, una heurística transposicional del conocimiento y una singular forma de intervención política" (OCAMPO, 2020, p. 3). Este ejercicio político, humano necesita de una investigación más allá de los métodos; con los métodos complejizados que vemos en lo que sigue. Pero, ¿Qué sentido tiene la inclusión? ¿Ha sido la inclusión parcela de algunas exclusiones?

Queremos provocar la justicia en todo sentido, la justicia de los saberes matemáticos en tanto el derecho a ellos todos tenemos; y con ese todo indicamos todas las personas; incluyendo su diversidad cultural, e intrinca como humanos, sus necesidades especiales; y acá aclaramos que concebimos que todos tenesmo necesidades especiales en algún ámbito de nuestra vida que debemos atender; la inclusión es "ante todo una provocación, efectúa un llamamiento a liberar el mundo de toda fuerza opresiva, reconoce el marcado carácter vacío de las políticas educativas para transformar el mundo y colocarlos en la senda de producción de otros mundos" (OCAMPO, 2019, p. 91). Pero, ¿desde cuándo, en el proyecto modernista se habla de inclusión, desde cuando se pregona acciones inclusivas? Desde hace mucho tiempo, la inclusión ha sido banderas de exclusión disfrazada del para todos.

Ahora en lo que sigue, debemos responder las interrogantes que marcan la indagación, hemos venido usando por ejemplo la palabra rizoma a diferencia de la tradicionalidad introducción, entre otras: ¿Qué son los rizomas? ¿Qué el transmétodo la deconstrucción rizomática transcompleja (RODRÍGUEZ, 2019b)? ¿Cómo cumpliremos el objetivo complejo? Declaramos que la denominación de rizoma de la indagación indica que "no hay un comienzo real sino en el medio (...) si todo encuentro es "posible" en el sentido en que no hay razón para descalificar a priori algunos caminos más que otros, no por ello todo encuentro es seleccionado por la experiencia" (ZOURABICHVILI, 2007, p. 95). 
Bajo los rizomas que indican conexión del todo, crisis y reconstrucción, volver a la crisis, definir categorías que van a clarificar conexiones y que son antigenealogías del síndrome modernistas: introducción, desarrollo, resultados y conclusiones que se imponen aún en centros de investigaciones: postgrados, revistas, bases de datos entre otras; nace la EDT y el transmétodo la deconstrucción rizomática. Con los rizomas el entramado se comprende como esencia de los transmétodos. De ahí se estará culminación de la investigación y aún regresamos a la crisis; y volvemos a la reconstrucción, enmarañando el objeto complejo; declarando a la insuficiencia de la construcción, aun cuando se cumple con el objetivo complejo, mediante el re-ligaje se siguen anidando transepistemologías.

Los transmétodos van más allá de los métodos tradicionales; necesita de los transmétodos pero para complejizarlos y decolonizarlos, conservando lo mejor de sí, lo incontaminado de dominación y reduccionismo; y la deconstrucción rizomática es una manera de descolonizar (RODRIGUEZ, 2019b); se trata de mostrar el desmontaje de la crisis de la exclusión de la Educación Matemática; para luego ir a la reconstrucción no definitiva inclusiva, donde el centro de la categoría EMDT se rectifica y anida aliñando posibilidades ricas de la matemática ciencia legado de la humanidad en la educación; al mismo tiempo desmitifica la idea tradicional de educar y toca la epistemología tradicional de la Educación Matemática que deviene en lo que sigue.

Se declara que esta indagación no complace las decadencias y estructuras modernistas, en tanto devine de un profundo cambio de mentalidad, de aceptación de la verdadera esencia compleja de la matemática; pero también en las estructuras subversivas de las tradicionalistas divisorias estatutarias: introducción, marco teórico, resultados conclusiones; va más allá de esto, complejiza en forma de rizoma conectando estructuras mentales complejas y decoloniales.

Se declara que, en los transmétodos, el sujeto investigador: la autora, es sujeto en primera persona con sus subjetividades y experiencia en la Educación Matemática por casi treinta años en la educación universitaria. No se releja la indagación a la objetividad exigida modernista, excluyente del sujeto investigador. Más ello, no le quita cientificidad a la indagación; si es emergente se leída y releída en mentes decoloniales para no desmitificar sus resultados por las negadoras investigaciones modernistas. 
Se realiza la Figura 1 a fin de presenta el presente rizoma en cuanto a su transmétodo y como se configura en la investigación. En la figura se narra como el transmétodo va a deconstruir en un marco decolonial planetario que se permite la aceptación y ejercicio de la transcomplejidad, donde el re-ligar, la ecosofía, y la antropoética conjugan el objeto complejo de estudio.

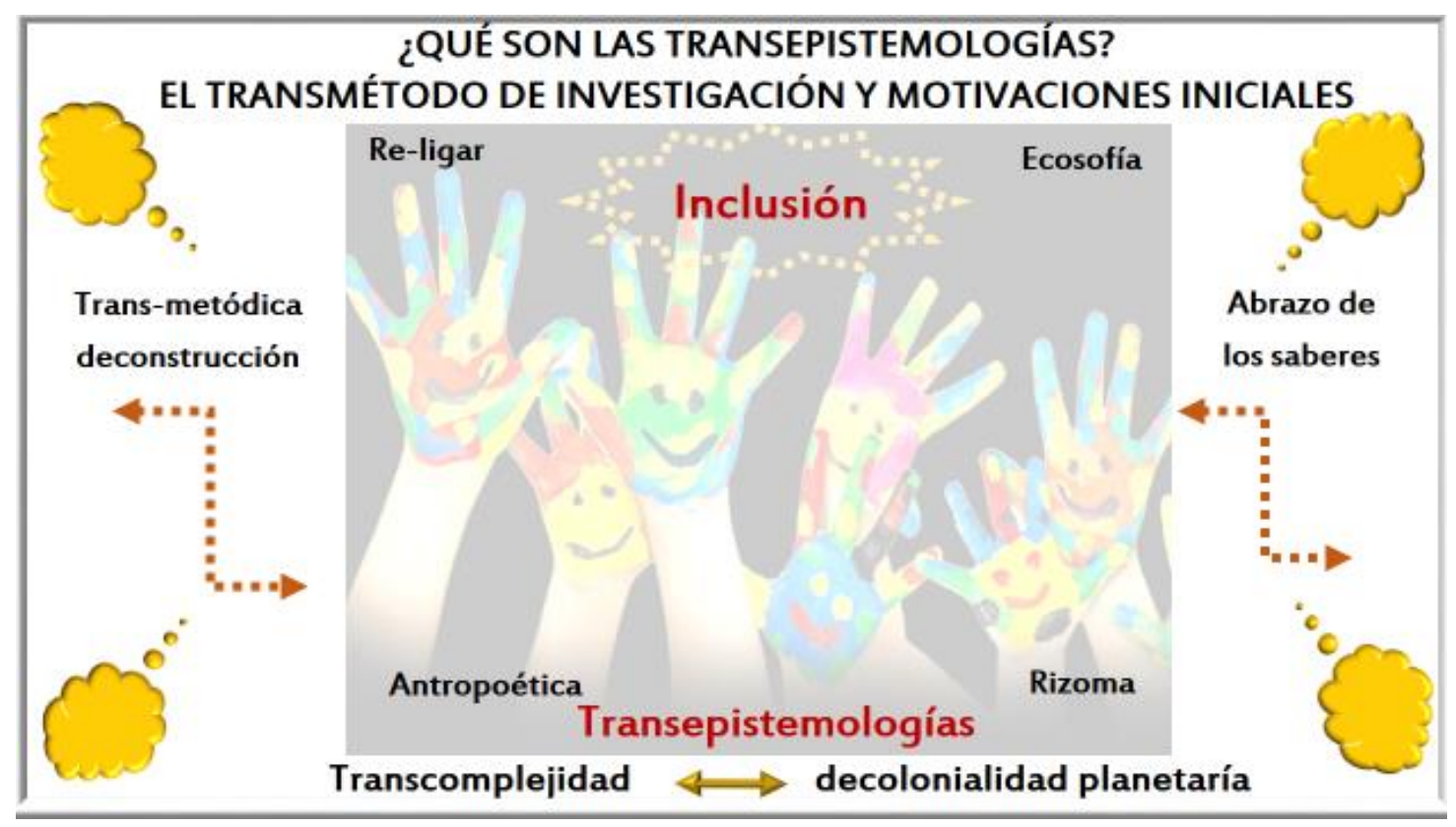

Figura 1: Elaboración del Autor

2 Rizoma deconstrucción de la crisis. Esencias de la epistemología de la Educación Matemática: exclusión y colonialidad

Deconstruir es decolonizar, decolonizar es develar los mecanismos de soslayación y exclusión. Precisamos que la colonialidad continuación del proyecto que nace con la colonización con la invasión a nuestro continente por Occidente desde 1492, en donde nos aluden doble culpabilidad: la de no haber estar civilizado; para ello no éramos personas, y la de resistirnos para hacernos ciudadanos con la cruel matanza y la expropiación de nuestros recursos (DUSSEL, 1992), conjuntamente con la transculturización y aculturización de nuestra cultura, proyecto modernista en tanto la historia del mundo para Occidente comienza con esa invasión y se perpetua hoy el dominio con diversos mecanismo en la globalización con el Norte de la colonialidad del saber, hacer, ser, pensar, soñar y existir.

¿Qué ha pasado en esta historia colonial hasta nuestros días con la Educación Matemática? Responder la pregunta sería dar esencias de la epistemología de la 
Educación Matemática catalogadas de exclusión y colonialidad. Declaramos que no haremos un recorrido de dicha epistemología en su secuencia; iremos a los puntos más connotativos de la crisis; andaremos a la raíz sin embargo; a los tentáculos del poder biopolítico; como lo denominamos: el des-ligaje de la biopolítica para el re-ligaje en la Educación Matemática Decolonial Transcompleja (RODRIGUEZ, 2020c); que son resultados de la mencionada línea de investigación. Queremos responder la pregunta inicial en este párrafo para luego desmitificar algunos aspectos excluyentes del recorrido epistemológico de la Educación Matemática.

En tanto en la colonización y en la colonialidad "la Educación Matemática ha venido siendo capaz de operar como un arma secreta del imperialismo occidental" (SKOVSMOSE y VALERO, 2012, p. 270), esto es la Matemática y su educación ha sido objeto de opresión y colonización en la invasión a nuestro continente; se presenta erróneamente la Educación Matemática como un sistema determinista. La gravedad de lo determinista, modernista, colonial olvidándose en el vaciado de reglas, fórmulas, teoremas, algoritmos, entre otros de la formación del ciudadano y su función política ante la humanidad; de la esencia histórica-filosófica de la Matemática, quedando la disciplina Educación Matemática solitaria en un lago donde la confluencia con las otras disciplinas no se toma en cuenta en su educación (RODRÍGUEZ, 2020d). Con excepción de grandes pedagogos. Como los pedagogos que siguen la Etnomatemática, que han aceptado la transformación de las mentes como ejercicio liberador.

Desde luego, con sus excepciones de estudios colaborativos de las Ciencias con la Matemática en el aula; donde no se transdisciplinan; sino que se llega a la multidisciplinariedad. Así se excluye la profunda transdisciplinariedad de la Matemática con todo modo de conocer, con: toda ciencia, todo constructo; todo saber no científico; la creación del universo en lenguaje matemático (GALILEO, 1963); en todo momento la huella de la matemática está presente dando legitimidad, consistencia, entre otros aportes indispensables en la historia de la humanidad. Estos hechos son execrados de la Educación Matemática tradicional. Es vivenciado por la autora de la investigación y por las voces que claman por la liberación ontoepistemológica de los actores de la Educación Matemática. Cuestiones difíciles de aceptar bajo la colonialidad de las mentes y la defensa de las viejas posturas soslayadoras de enseñar. Se invita a inmiscuirse en la basta literatura 
que devela la crisis de la Matemática en el aula.

En esa epistemología tradicional debemos concientizar el hecho de que la imposición de la mal denominada Matemática Occidental ha sido profundamente excluyente de los aportes del patrimonio matemático de civilizaciones como las egipcias, los mayas, los aztecas; entre otros. Es notorio que la Etnomatemática recoge estos resultados; pero no se profundiza en la indagación. Es bien sabido, de investigaciones decoloniales la importancia en particular de los sistemas de numeración maya y egipcio; las visiones rizomáticas de ellos se muestran en el texto recién publicado (RODRÍGUEZ, 2020e).

En esa epistemología tradicional de la Educación Matemática escasea un verdadero dialogo, en este sentido, "sin diálogo, el ser humano se asfixia" (PANIKKAR, 1993, p. 1148). Y esa manera de imposición especialmente donde el discente se cree no capaz de aprender, donde la predisposición abunda y el rechazo hacia la ciencia y el discente es muchas veces la norma impide un crecimiento de confianza y afectividad para emocionarse y aprender; hoy es bien sabido lo importante de emocionarse para aprender positivamente disfrutando, jugando al geómetra (RODRÍGUEZ, 2020d); esta tendencia tiende a cambiar con otros instrumentos como la tecnología; aun así la franja critica de estudiantes aplazados en matemática sigue siendo también la norma.

Es así como, la Educación Matemática hoy es negadora de la ecología de los saberes: por un lado se impone una forma definitiva de aprender y hacer en la Matemática Científica Occidental y las Matemáticas no escolares quedan en aplicabilidades pocas veces vistas, en irrealidades de problemas del discente que la mayoría de la veces el no vivencia (RODRÍGUEZ, 2020d). Una arma impuesta en la reducción y dominio de unos conceptos tronchados de la Matemática, obstaculizando ante la vida del discente la profundad transdisciplinariedad de la ciencia en cuestión; su presencia en la vida cotidiana; obviando las creencias negativas; negando la subjetividad (RODRÍGUEZ, 2020d).

En la epistemología tradicional de la Educación Matemática es bien sabido que se "ha impuesto una matemática fría, colonial y dedicada a unos pocos llamados inteligentes; el pensamiento abismal que ha negado la ecología de los saberes en el proceso de enseñanza-aprendizaje" (RODRÍGUEZ, 2020f, p. 3). Es inminente un estado de 
disciplina incomunicable que se dedica a imponer procedimientos definitivos. Ahora en época de encierro, de cuarentena, la autora ha presenciado, por ejemplo, pese al uso de las tecnologías, evaluaciones exageradas para el tiempo de realización, la poca asesoría del docente y se ha ampliado la inclusión; pese al agrado de la tecnología en la mayoría de los casos la matemática se aprende cada vez menos.

Es de declarar que por el transmétodo de investigación las subjetividades de la autora están presente permeando la dialéctica de la investigación; la experiencia de la autora investigadora junto a sus aportes va de manera liberada en el discurso. Es importante aceptar que la autora no está comprometida con las investigaciones modernistas donde el autor permanece objetivamente sin aportar a la indagación,

Desde luego, el proyecto decolonial ante el atentado a la esencia de la Matemática y la condición humana de los actores educativos se instala frente a procesos de arrogancia epistémica (RESTREPO e ROJAS, 2010). ¿Relaciona el aula tradicional de matemáticas y la arrogancia? ¿El docente impone un control del cuerpo y de la vida del discente con la repetición sin comprensión de la matemática? Desde luego que sí, se ha propuesto en medio de la mencionada línea de investigación que se realice el des-ligaje de la biopolítica para el re-ligaje en la Educación Matemática Decolonial Transcompleja como se mencionó anteriormente.

Todos estos procesos excluyentes que ya hemos venido profundizando en investigaciones en consonancia con el objetivo complejo dan cuenta de la necesidad de una Educación Matemática Inclusiva; que no sólo atienda la inclusión en tanto la toma de vitalidad y potencialidad matemática para aprender de las personas con necesidades especiales; sino que atendiendo estas necesidades urgentes se considere la Matemática como una necesidad especialísima de enseñarse, atender los estilos de aprendizaje, el ritmo, el tiempo, la diversidad cultural, tener en cuenta los procesos dialógicos-dialécticos del discente; es más provocarlos aprovechando la esencia de las concepciones de la Matemática: introspectiva, profunda, transdisciplinar, compleja; en la reconstrucción que deviene daremos algunas visiones esenciales a considerar para minimizar todas las exclusiones que hemos venido perfilando.

Precisamos, en la medida de lo posible lo que significa un proceso dialógicodialectico. El dialogo dialéctico está orientado a la "discriminación entre verdad y error 
mediante el pensamiento" (PANIKKAR, 1999, p. 27), este tipo de diálogo parte de la hipótesis de que los participantes cooperan en una racionalidad, como el principio de no contradicción, y de ese modo pueden someter sus perspectivas a la audiencia de la razón; ello se pretende aplicar en los conceptos de la matemática y se conoce de los diálogos de Platón, Sócrates entre otros. El diálogo dialéctico, si bien tiene su lugar en ciertos ámbitos de la vida humana, es insuficiente para asumir los retos de la interculturalidad (PANIKKAR, 2003); así en la educación la comunicación es posible y debe ocurrir en un nivel diferente al de la dialéctica; pero desde luego no divorciada de ella.

Por ello, en el diálogo dialógico somos consecuentes de que los conceptos que manejamos germinan de una fuente más profunda. No sólo permito que el otro me conozca; sino que llego a conocer excelentemente mi propio mythos mediante las críticas y descubrimientos de mi interlocutor.

\begin{abstract}
El diálogo dialógico no tiende ni a la victoria en el contexto de las ideas ni a un acuerdo que suprima una auténtica diversidad de opiniones. El diálogo dialógico busca, si acaso, expandir el campo de comprensión, con la profundización por parte de cada interlocutor de su propio campo de comprensión y la apertura de un posible lugar para lo (¿todavía?) no comprendido (PANIKKAR, 2003, p. 67).
\end{abstract}

Como podemos ver, el diálogo dialéctico es sobre objetos, en este caso matemáticos, sobre sus doctrinas, temas o problemas que se tratan en la ciencia; pero el diálogo dialógico es entre sujetos, entre docentes y discentes, porque el dialogo entre ellos en la Educación Matemática es sobre ellos mismos y de ese modo consiguen entrar cada uno en el universo cultural del otro. Al no considerar la cultura, cotidianidad de la Matemática; cuestión en la colonialidad de la Educación Matemática: ser inclusivos de los aportes matemáticos; inclusivos del Sur y de los países soslayados; entre otros; o del hábitat popular de los discentes y sus subjetividades; es imposible bajo el proyecto modernista producir fructíferos dialógicos-dialecticos en la enseñanza de la Matemática.

Desde luego la crisis de la Educación Matemática, en un recorrido epistemológico secuencia, en lo posible podría ser detallado más adecuadamente. Para efectos de la investigación hemos tocado los tentáculos más neurálgicos. Clarificamos la necesidad de la complejización de todos los aportes de las civilizaciones, sobre todas las del Sur, en su patrimonio histórico y recorrido que aportarían esencias a su patrimonio histórico y en general a la Matemática como ciencia legado de la humanidad. 
Se resume el presente rizoma la Figura 2 siguiente. En donde se narra la esencia de la epistemología de la Educación Matemática que se ha venido mostrando como excluyente y colonial en el paradigma de la modernidad. Se explicitan preguntas importantes a tomar en cuenta en la problemática; entre ellas el divorcio entre los saberes matemáticos.

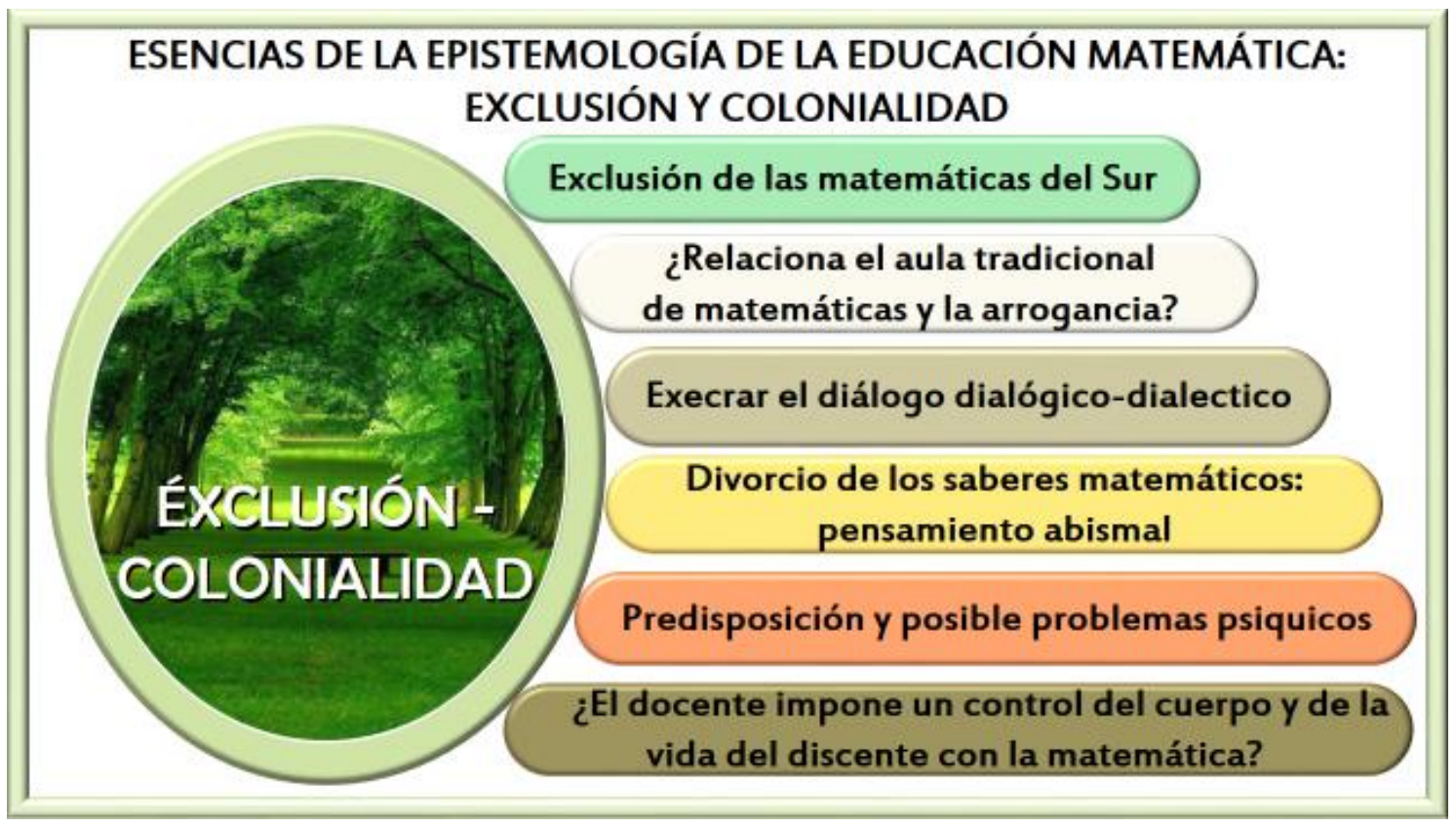

Figura 2: Elaboración del Autor

3 Rizoma reconstrucción. Transepistemologías inclusivas en la Educación Matemática Decolonial Transcompleja

En este rizoma se presentan resultados de la indagación que permiten cumplir con el objetivo complejo de la indagación. La transepistemología que deviene de la visión transparadigmática transcompleja ratifican el hecho, de que "la complejidad es incompatible con la segregación del sujeto propia del determinismo y en muchos casos el enfoque reduccionista destruye la circunstancia de estudio y ha llevado a la ciencia a alcanzar sus límites" (MANZANARES, 2016, p. 43). Es así como, fuera de los dogmas epistemológicos y metodológicos coloniales de la Educación Matemática se encuentran saberes interconectados de las Matemáticas científicas y no científicas; aun cuando no estamos de acuerdo con esta división. Por ello, una vez desligado del pensamiento abismal Occidental que formo dichos topois vamos con la EMDT a re-ligar los saberes matemáticos; que denominamos así desde ahora en la deconstrucción y declaramos que el único apellido que tiene la matemática es: la humanidad. 
Como la transdisciplinariedad en este caso va en consonancia con la complejidad entonces también con la transepistemología, que en primer lugar se apropia de la sustancia subversiva; es esta las primeras esencias de las transepistemologías de la Educación Matemática; donde ocurre

\begin{abstract}
La transgresión de la dualidad oponiendo los pares binarios: sujeto-objeto, subjetividad-objetividad, materia-conciencia, naturaleza-divinidad, simplicidad-complejidad, reduccionismo-holismo, diversidad-unidad. Estas dualidades están transgredidas por la unidad abierta englobando el universo y el ser humano (NICOLESCU, 1996, p. 44).
\end{abstract}

Traducimos esta transgresión a la diferenciabilidad que se ha venido haciendo en la Educación Matemática; tales como los binomios: abstracto-concreción, teoríapractica, global-local, micro-macro, cotidiano-científico, subjetivo-objetivo, puntualgeneral; entre otros que ha venido ocurriendo en la Educación Matemática; la separabilidad de esas diadas es eminente desde el reduccionismo; pero la realidad es que no hay concreción sin abstracción.

Por ejemplo, en la Educación Inicial, los niños y niños aprenden Matemática desde la concreción y van poco a poco llegando a la abstracción; en el medio de su concreción ellos conciben ideas cotidianas de abstracción en su representatividad mental, que ha sido tradicionalmente tronchado por los docentes, imponiéndoles juegos y realidades de ellos y no de la vida del niño y niña (RODRÍGUEZ, 2020d).

Ellos, en crecimiento metacognitivos de alto nivel necesitan sus juegos, tienen sentido y vida en su imaginación y reglas de sus propios juegos de números, sentido de desplazamiento, noción de tiempo. Temporalidades que deben ser anidadas con sus subjetividades; esa manera inédita de ir estudiante el crecimiento lógico matemático, juntamente con su inteligencia compleja que permea estrategias complejas es digno de revisar; y ha estado en estudio en la línea de investigación: Educación Matemática Decolonial Transcompleja.

Por lado, sin separabilidad en el discurso complejo, en el pensar rizomático, la transepistemología "debe asumir lo entrelazado de lo científico, económico, educativo, tecnológico y lo humanístico con el compromiso social (...) con preeminencia ética" (PERALTA y ZAMBRANO, 2016, p. 51). No hay duda que investigar en EMDT debe estar fuera de los ejercicios de poder, con un espíritu democrático, antropoético y el 
ejercicio de solidaridad humana antropolítica. De ello deviene otra esencia o sustento de las transepistemologías: las investigaciones con bases antropolíticas y antropoéticas que tocan el aspecto ético abandonado por las indagaciones modernistas.

La antropolítica, la política del género humano, el servicio a la formación del ciudadano político al servicio del planeta tierra conlleva a ampliar el lente de investigar en tanto transcender las barrearas simplista del conocimiento; baja de un pedestal el conocimiento elitista de la matemática para democratizar el saber (SKOVSMOSE y VALERO, 2012). Es urgente entonces la magnificación de la investigación, en tanto una insurrección modernista debe ocurrir; investigando su propia práctica; el docente dudando y re-ligando lo que supuestamente sabe, poniendo en duda sus propios preceptos. Ya su praxis no está endiosada por una soberbia que él es que sabe y los demás atienden sumisamente. La sospecha de que así me enseñaron a mí y así repito ha caducado.

Un elemento clave en el proceso investigativo estratégico es salir de la disciplina Educación Matemática indisciplinándola, la transdisciplinariedad complementa muy bien; es decir trascender para poder generar procesos emergentes y religados, general lo emergente, el sujeto trasciende, pensé y generé sus respuestas o nuevas preguntas en el proceso investigativo (GONZÁLEZ, 2020).

En esas investigaciones debe estar presente: que no existan franjas de marginación de personas, en tanto todas pueden aprender matemáticas; la diversidad en los estilos y subjetividades muy particulares en los que los individuos aprenden; la especial atención a la condición humana; pues la Matemática converge en el ser en su conversión a metacogniciones más elevadas en tanto se comprenda la especialísima función de educar y la responsabilidad de aprender a pensar y de retraerse en la dignidad humana con el aporte de las Matemáticas. Todo ello necesita de una responsabilidad antropoética.

La antropoética va a la democratización; pero también el hecho humano y ético de educar con la matemática; es una actitud en formación que se manifiesta en la praxis, que supone "la decisión consciente y clara: de asumir la humana condición individuosociedad-especie en la complejidad de nuestra era, de lograr la humanidad (...) asumir el destino humano en sus antinomias y su plenitud" (MORÍN, 1999, p. 101). Es así como en la formación de científicos y profesionales esta desde la transdisciplinariedad con los aportes de la Matemática; pero también se trata de una antropoética en la ciudad, en el 
hábitat popular, en donde quiera exista un ser humano; esta ética del género humano no es elitista de las instituciones educativas; es también la del político que con sus decisiones desangra a la humanidad (RODRÍGUEZ y MIRABAL, 2020). Las transepistemologías se unen a ese sentido de vía y buscan sus aportes en tanto siempre es posible la consideración profundamente humana y temerosa del respeto a la vida en todas sus formas.

Entonces, en esa transepistemología emergen solidaridades sólo posibles en miradas decoloniales planetarias; en tanto el conocer cotidiano que tiene el discente se reinterviene en esa aula mente social: un espacio subjetivo para aprender matemática en todo lugar y tiempo que transciende el espacio físico del aula (GONZÁLEZ, 2015). Regresamos así al rescate de los saberes matemáticos conocidos en especiales connotaciones por los discentes fuera de la regularidad del lenguaje matemático conocido; pero que al docente reconocerlas como valioso las puede estudiar y avanzar hasta hacerlas generales y comprensibles en el lenguaje matemático. Estas transepistemologías tienen entonces un sustento especialísimo: el sentipensar; que era prohibitivo en las subjetividades execradas del sentir y emoción a cambio de la pragmática de la repetición incambiable con algoritmos fijos.

El sentipensar en la formación del ser humano con la matemática no es vanidad ni antojo si tomamos en cuenta la condición humana del discente "el hombre sentipensante que combina la razón y el amor, el cuerpo y el corazón, para deshacerse de todas las (mal) formaciones que descuartizan esa armonía y poder decir la verdad" (FALS, 2015, p. 10). Ese ser en toda su complejidad debe estar comunicado y conectado con el hacer Matemática, su reconstrucción, sentir y vivir sus creadores, su pensar y necesidad de reinventar la Educación Matemática en cada ser humano que se apropie de ella.

Pensado de manera compleja entonces el sentipensamiento es una síntesis afortunada, "porque condensa muy bien nuestro carácter estético primordial, dado que el sentimiento es de tal orden: antepuesto a todo ejercicio de pensar, sea cognitivo, ético, político o científico" (RESTREPO, 2017, p. 212). Es sin duda en sentipensar una categoría decolonial primerísima en la educación que incita a imbuirse más allá de la racionalidad, hacia los procesos emotivos, es bien sabido que el cerebro aprende mejor cuando se emociona y no se cohíbe con restricciones de la imaginación; en la tetra: cuerpo-mente-alma-espíritu en plena complejidad en enseñanza (RODRÍGUEZ, 2020e). 
Por ello, los discentes se emociona en conseguir contenidos matemáticos en su vida, se retroactúan y re-ligan en su sentipensar, en sus emociones en colocarle números, medidas, ángulos a sus conocidas figuras de sus juegos, por ejemplo; pero ellos también entienden de dureza y de materiales; el pescador porque sus padres y cultura es de pescadores entiende entonces las separabilidad de las redes de pescar en tanto el tipo de peces de la época del año y de ahí existen una convulsionada Matemática que emerge digna de remasterizarse en muchos libros, programas en la red de internet y compartir con otras culturas; donde el encuentro y conexión es la Matemática amena digna de reconstruirse en transepistemologías sentipensantes que recobran la emotividad y el amor por el conocerla.

Es así como, la Matemática de los grupos execrados de la construcción matemática, los patrimonios culturales e históricos no contados; los no reconocidos en su patrimonio matemático entran en escena por la puerta grande de las Matemáticas, con sus saberes matemáticos; los mayas, los egipcios son culturas con un desarrollo matemático de alto nivel digno de recrearse en las ávidas mentes de los jóvenes para salvaguardar el legado. El momento actual es propicio para que en todo lugar la Matemática se devele cómo se da en los procesos dialógicos, cotidianos y subjetivos de los seres humanos; donde desde el hogar cada uno puede ser portador potencia pedagogo de la matemática. El re-ligar des-ligando primeramente, puede hacernos ver cómo es necesario darnos cuenta de que la verdad única nadie la tienen, y que sin embargo, no por ello el poder biopolítico del momento pierde oportunidad para ejercer su conveniencia en las falsas políticas educativas; que se disfrazan de decoloniales (RODRÍGUEZ, 2020f).

La escritura maya, su sistema se denominan jeroglífico maya, ya que se trata de un conjunto de glifos muy elaborados y algunos historiadores los han relacionado con la escritura manejada en el antiguo Egipto (RODRÍGUEZ, 2020f). Sin importar la relacionalidad es importante explorar los sistemas de numeración de las dos culturas que nos llenan de emoción en tanto el avance de las culturas y su historia estuvieron centrada en la construcción y sus apostes de la matemática y que han sido soslayados y hasta en epistemicidios en sus códices y papiros.

Es importante clarificar, que pese a los epistemicidios cometidos luego de 1492 con la masacre en la invasión controlada y desvirtuada luego a nuestro continente; la 
cultura maya aún existe que muy por el contrario en contra de las teorías de muchos historiadores que dan por desaparecida a la cultura maya, "puede afirmarse categóricamente, que el pueblo maya, su cultura y su cosmovisión persiste sostenida por millones de personas que siguen habitando el área mesoamericana, hablando idiomas de clara y antigua raigambre mayense" (MATUL, 1996, p. 153).

La civilización maya, fue la primera cultura en el mundo en conocer el número cero (0) y su abstracción (MAGAÑA, 2006), alrededor de 400 años antes de nuestra era, anticipándose en seiscientos años a las culturas de la india en este descubrimiento. Entre tanto bagaje de creación matemática, se le conoce por sus magníficos logros astronómicos, culturales, agrícolas arquitectónicos, médicos, astronómicos, entre otros y es uno de los pueblos precolombinos más atractivos del Sur a los ojos de la sociedad globalizada de hoy. Los mayas fueron capaces de desarrollar un poderoso sistema de cálculo con el que concibieron un calendario más preciso que el calendario civil que hoy utilizamos y que realizaron cálculos para predecir, con asombrosa precisión, acontecimientos astronómicos que siguen cumpliéndose (RODRÍGUEZ, 2020f). Es notorio que se reescriben transepistemologías profundamente inclusivas de los saberes matemáticos del Sur, de las civilizaciones colonizadas. Que recobran en el mundo el digno derecho a conocerse y recrearse en la EDMT y sus actores emotivamente en evolución sentipensante.

Consideramos de especial interés transepistemologías que por su grado de complejidad e inclusión las perspectivas del ser, desde sus complejizadas variantes como lo humano, tecnológico, económico, político, ético, cotidiano, filosófico, estético, afectividad, creatividad, lo normativo, la costumbre, intuición y espiritualidad (RODRÍGUEZ, 2019c); en todas ellas la EMDT tiene su aporte y sello de originalidad para formar al ser en la manera de vivir inclusiva-ecosófica; este último el arte de habitar en el planeta; la sabiduría que nos lleva a cohabitar con los saberes; en ese aporte transdisciplinar y transversal. Todo ello regresa el sentido de la historia y filosofía de la Matemática, la conjunción Platón y Pitágoras, la espiritualidad de los pitagóricos en tanto el disfrute y la formación como arte no apresurado del resultado; sino el deleite por saber, por hurgar en lo más íntimo de los procesos metacognitivos.

En las transepistemologías inclusivas, se da apertura y significación al concepto de inclusión verdaderamente complejo, esto es en toda su significancia y no aquel 
supeditado a ciencia, saber alguno personas de manera personalizada; la inclusión no es parcela, los incluye, los retracta y jamás los excluye en todo sentido siempre incluye las diversas posturas, personas; pues la modernidad ha usado la inclusión y lo ha parcelado, usado para excluir, es esencial el considerar que la inclusión y hacer educación inclusiva de la matemática "constituye un campo transcientífico" (OCAMPO, 2018, p. 30); por ello no se debe a posturas excluyentes. Transcientífico incluye lo científico, complejizado e inclusivo.

Estas transepistemologías anidan una educación inclusiva ecosófica de la matemática; La Educación Inclusiva Ecosófica atiende en una responsabilidad social marcada e imprimida de la necesidad de liberación de los no incluidos, de los olvidados, de los soterrados, de las personas con necesidades educativas especiales, entre otras; pero también de las falsas políticas educativas (CARABALLO y RODRÍGUEZ, 2019); esa esencia a la Educación Matemática le anida un proceso de responsabilidad antropoética ante los actores educandos y la transcendencia de la ciencia legado de la humanidad; y sus aportes en la tierra - patria.

En este sentido la inclusión "es ante todo una provocación, efectúa un llamamiento a liberar el mundo de toda fuerza opresiva, reconoce el marcado carácter vacío de las políticas educativas para transformar el mundo y colocarlos en la senda de producción de otros mundos" (OCAMPO, 2019, p. 91). Debemos comprender que el ser humano ha anidado una opresión psíquica desde niño, al sentirse que no pueden llegar a sus teorías, que no pueden comprender ese hecho los excluye ante su educación en general; los niños o individuos que han estado bloqueados "para aprender matemáticas, han estado bloqueados también en su personalidad. Un niño que no aprendió matemáticas se siente disminuido en sí mismo como individuo. Se puede hablar, pues, de una relación profunda entre el conocimiento matemático y la personalidad" (PÉREZ, 1980, p. 44).

Mientras que con la educación inclusiva de la Matemática en toda su complejidad se quiere pensar profundo, ver en donde el pensar disyuntivo impidió la metacognición de alto nivel, George Papy lo afirma que las Matemáticas nos vinculan con el ser, con la realidad "constato que las matemáticas tocan estructuras psicológicas profundas (...) podemos decir que el dominio del lenguaje matemático ejerce un efecto terapéutico" (PÉREZ, 1980, p. 45). De esa inclusión psicológica-psíquica que es elemental en las 
condiciones humanas de los actores educativas está redefiniéndose la epistemología tradicional de la Educación Matemática; para ir a transepistemologías profundamente inclusivas del ser y la matemática en su completitud.

La educación inclusiva ecosófica como es por ejemplo, la Educación Matemática Decolonial Transcompleja (RODRÍGUEZ, 2020b) es grandiosa, pues se nutre de estos grupos de estudiantes en toda su diversidad, que en la mayoría de los casos no son tomados en consideración; la franja critica delineada como imposibilitada como exclusión colonial para aprender matemática; allí como ya se dijo se encuentran las personas mal llamadas de colores - en muchas partes aún existe racismo en la educación), los afrodecendientes —, las mujeres en un comienzo, las personas de la franja de economía en crisis sobrevivientes en sus necesidades mínimas; estos hechos han atentado contra la dignidad humana. Por ejemplo, las lenguas aborígenes autóctonas, originaria en el planeta son llamadas a patrimonios culturales que en las instituciones educativas pueden transcender a los que no la conocen, y de allí con la globalización puede ser conocidas en el mundo entero (CARABALLO y RODRÍGUEZ, 2019).

Por ahora, y en medio de las reconstrucciones como esencias, des-ligajes y religajes en la praxis de las epistemologías, al haber develado la carencia de los procesos dialógicos-dialecticos en la Educación Matemática vamos a su inclusión como premisa que la Educación Matemática Decolonial Transcompleja es dialógica y reta el poder de análisis que tenemos dormidos esperando ser provocados a fin de llegar a procesos metacognitivos de alto nivel.

En tal caso, debemos re-ligar en la transmodernidad, como proyecto decolonial planetario, para estar formados a fin de producir diálogos dialógicos-dialecticos en la Educación Matemática; ello es urgente en la formación del docente una enseñanza transdisciplinar y compleja donde las matemáticas se entrelazan con las diferentes disciplinas, dando respuestas o explicación a fenómenos ambientales, y literarios, haciendo de las Matemáticas un recurso, de su enseñanza un acto ameno, agradable y de su aprendizaje un proceso que transgreda las fronteras disciplinares, estableciendo puntos de encuentro entre las Matemáticas y la Literatura, el Ambiente, la Química, la Física, la Geografía, la Historia. Todo ello, es punto de encuentro con el re-ligar de la autora, a fin de estar formada para que en la enseñanza se lleve al discente a que pueda relacionar las Matemáticas con su cotidianidad, cultura y procesos de convivencias y juegos. 
La inclusión tan necesaria acude a la esencia de la Educación Matemática Decolonial Transcompleja, que se concibes para la resistencia que involucra desde un trasfondo dialógico-dialéctico, "educar en la reflexividad, el asombro, la resistencia y la percepción de las transformaciones sociales, incorporar la teoría compleja, invita a integrar la relación individuo-sociedad-especie, trilogía desde la cual se pueden superar las cegueras educativas y reorganizar el conocimiento" (ANDRADE, LEGUIZAMO y VERGARA, 2018, p. 495).

En las mentes de los que enseñan matemáticas deben ser apreciadas otras formas decoloniales de concebir el conocimiento, que hasta ahora, en la mayoría de los casos es: excluyente frío, mecánico, inerte, impuesto y provisto de ejemplos clásicos de irrealidades, por ejemplo; en este caso en el Sur tenemos claridad y pertenencia de cotidianidades llenas de saberes matemáticos que pueden anidar otras realidades que aviven el interés por aprender matemática (RODRÍGUEZ, 2020e). Son transepistemologías que se van reconstruyendo en el calor decolonial y el entusiasmo por aprender, con una profunda fe en el educando; en ese ser humano que tiene potencial y sensibilidad que necesitan ser provocada por el docente.

Al final, en un comienzo exploramos la inclusión una vez más de la categoría ecosofía siendo las transepistemologías de la EMDT profundamente ecosófica, volvemos rizomáticamente a ello para clarificar un poco de profundidad: la ecosofía es la conjunción de la ecología social, espiritual y ambiental, las tres ecologías (GUATTARI, 1996). ¿Cómo se incluye como necesidad urgente esa sabiduría complejizada de habitar en el planeta: la ecosofía? La matemática en un dialogo dialógico-dialectico puede bien, como en los inicios de la Matemática en las civilizaciones provocar un estado de conciencia de nuestro accionar en el mundo, las necesidades de identidad tanto individual como planetaria, para saber vivir y convivir desde el amor por nuestra creación en una sola tierra-patria; con conocimiento pertinentes; la formación para la toma de decisiones adecuadas; es inclusión es urgente.

Para ello, se debe des-elitizar, re-ligar, des-ligar con las disciplinas conjuncionándolas, indisciplinando las disciplinas; rompiendo sus fronteras fuera del pensamiento abismal que las separa, la responsabilidad social del docente como ciudadano, y la esencia misma de ser humano; una transversalizándola a los saberes 
matemáticos; que son simple y grandemente saberes del mundo y para el mundo. Para ello, y es motivo de la continuación de la línea de investigación provocamos la inclusión ecosófica en las transepistemologías con los campos ecosóficos, para futuras investigaciones: esto es: científico, emocional, práctico y espiritual. Así, las concepciones de la ecosofía son el puente unitivo de los saberes en general donde siempre la matemática tiene su aporte; hagamos realidad este sentido en la Educación Matemática.

En lo que sigue se presenta la Figura 3 resumir el rizoma actual. Los resultados de la investigación de indican que la decolonialidad le permite la inclusión; la ecosofía permite adquirir sabiduría desde la matemática y su comprensión en procesos metacognitivos de alto nivel. La diatopia el abrazo de los saberes matemáticos, incluyendo los de la cotidianidad, cultura, entre otros. Todo ello con políticas educativas re-ligadas y des-elitizada.

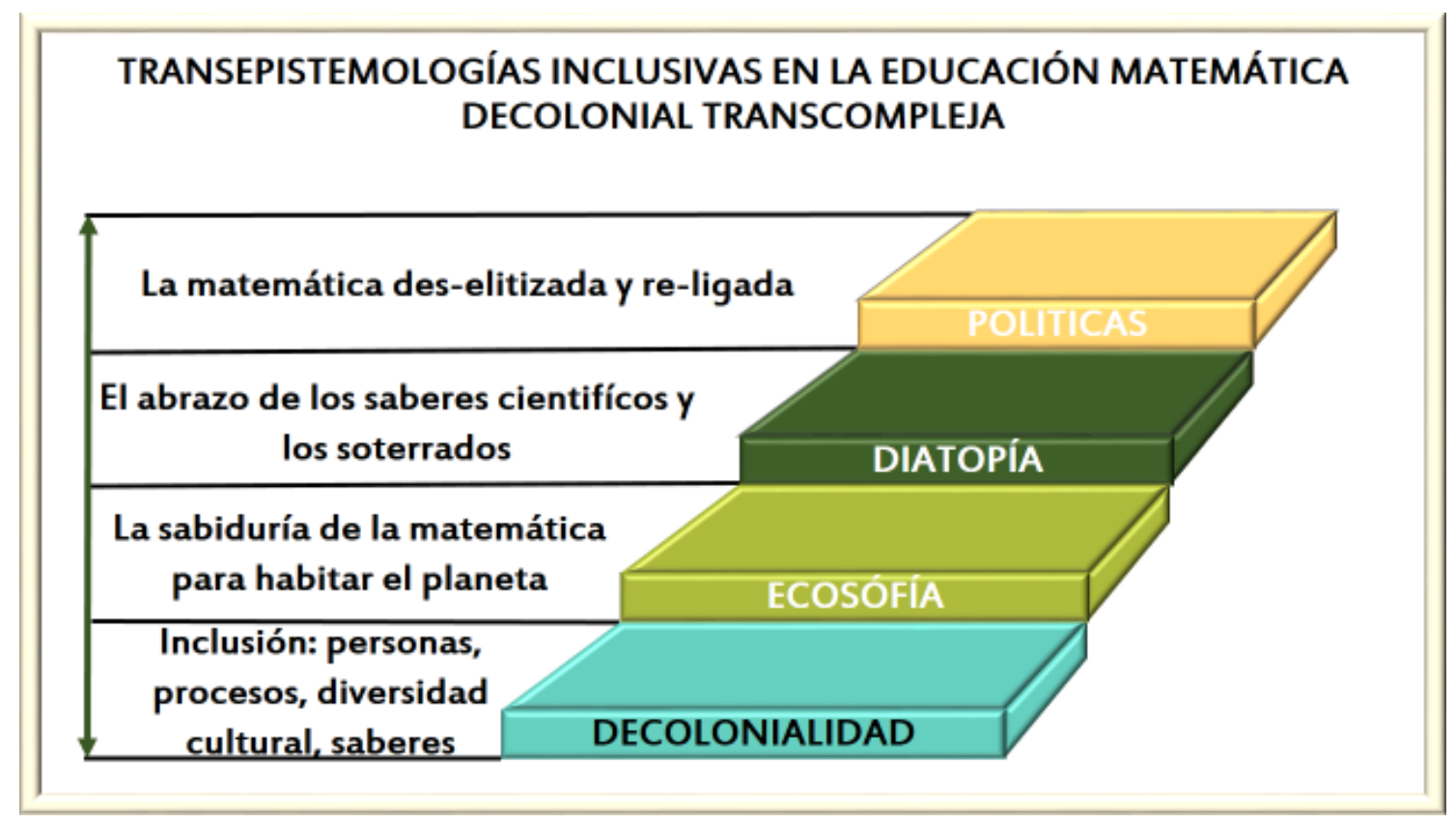

Figura 3: Elaboración del Autor

4 Rizoma conclusivo. Clausura con principios inclusivos de la línea de investigación Educación Matemática Decolonial Transcompleja

En este momento propositivo del transmétodo hermenéutica comprensiva, seguimos con los rizomas anteriores; Se han analizado transepistemologías inclusivas en la educación Matemática Decolonial Transcompleja como objetivo complejo de investigación. Es urgente desmitificar la inclusión definitiva; la concepción acabada en tanto la concepción de la EMDT es la apertura permanente. En tanto ella se re-liga como 
esencia principalísima por su propia concepción. Es peligroso, en arenas movedizas excluyentes como la colonialidad como proyecto soslayador pensar que se puede ser inclusivo.

Es espacios transepistémicos vamos a desmitificar viejas herencias, por ello desligar es primerimo en la EMDT; ella como línea de investigación tiene una tarea día a día en donde los tentáculos de artefactos soslayadores mutan engañando cual pasivos e inclusivos para seguir inoculando en la mente de los actores educativos rezagos de exclusión, en un lema de la Matemática para todos. La conciencia antropoética convoca a la humildad y el ejercicio de poder en la palestra de la evaluación del docente de Matemática. ¿Seguro que somos seres inclusivos con una apertura a la ciencia legado de la humanidad en toda su complejidad ante la humanidad del discente?

No soy reguladora de proceso ajenos, en tanto mi regulación y evaluación como matemático y como docente está en marcha; soy víctima del proceso y formada excluyentemente; pero batallo en las aguas movedizas para no repetir ante el discente soñador y esperanzado de ser tomado en cuenta mi historia con-formativa. Pero, debo decir a favor que haber estudiado Matemática como primera carrera universitaria es una bendición de Dios que me ha permitido permear los denominados erradamente otros saberes. Hoy complejo que sólo existen saberes, que sin científicos y al mismo tiempo cotidianos; que todos podemos aprender Matemática. Entiendo, la autora que la Matemática, que me presentaron en mi formación carecía de su valiosa complejidad; que en la medida que la develo en mi corazón y sentir entro en un re-ligar de mi conciencia de la belleza creación de Dios en lenguaje matemático.

La inclusión categoría especial en la Educación Matemática entonces, al final podemos decir que está justificada en sus necesidades; pero que debemos tener cuidado de que el espacio transparadigmático no puede estar enmarcado en la modernidad que ha sido el causante de la no inclusión: la exclusión en todo sentido. Y entramando las necesidades la transmodernidad es el proyecto decolonial por excelencia para seguir religado transepistemologías en una de las ciencias, la Educación Matemática, más excluyente aún hoy. Excepto casos exitosos maravillosos de transdisciplinariedad, etnomatemática; entre otros.

Con lo anterior, como culminación en un comienzo acalorado de la inclusión; de 
mi texto las matemáticas del amor y la amistad (RODRÍGUEZ, 2018) quisiera incluir un poema en versos libres que rescatan la belleza de la matemática, muestra de que es posible incluir dicha ciencia con todas las subjetividades en la vida del discente; le invitos a ellos a hacerlos praxis, volver con Paulo Freire quien en el año 2021 cumpliría 100 años de su nacimiento; no es sólo teoría es la praxis y la liberación necesaria. En lo que sigue, el poema titulado las asíntotas: el amor más grande e imposible:

Las asíntotas son las historias de amor, o de amistad imposibles que nunca pudieron ser, que nunca se juntaron, utopías irremediables del destino.

Oh amor eterno mi alma gemela de mi clase consecuente de sentimientos que creces como yo; cuan destinos separados tenemos. Sí, ese eje de simetría que nos refleja es tan visible, tan real; pero al mismo tiempo un recordatorio que nunca nos podremos juntar.

Cuan bella curva cóncava hacia abajo tanto tú como yo, en algunos casos; sí que crece que se suaviza algunas veces; como es tan cruel ese destino de mirarnos cada uno desde sus cuadrantes y no poder tocarse. (RODRÍGUEZ, 2018, p. 12).

Como es posible que los dos nos acercáramos tanto a ese lugar, ese eje de las ordenadas donde nos miramos cada vez más cerca y no pueda sintiendo tu respiración tu palpitar conseguir ese punto de intersección, que nos daría la posibilidad de realizar nuestra unión.

Cuan 1+1=1 que maravilloso seria que mi amor asíntota fiel al eje de mi vida si pudiera en ese punto realizar nuestro amor e irnos sin importar si fueran fracciones de tiempos nuestra conjunción al permutar al cielo la realización de nuestro amor.

Sin esperanza seguiremos, pues en el transcurrir del tiempo ¡la imposibilidad de realizar nuestro amor se hace eterna! En esas crueles curvas asintóticas.

En mi profunda subjetividad como autora de la indagación, cristina, en la ecosofía espiritual libre de ejercer en los transmétodos, al despedirme quiera decir de mi gratitud a Dios amado en el nombre de nuestro salvador Jesucristo: “'Alaben al Señor porque él es bueno, y su gran amor perdura para siempre!" (1 Crónicas 16:34), porque siempre "hermanos, siempre debemos dar gracias a Dios por ustedes, como es justo, porque su fe se acrecienta cada vez más, y en cada uno de ustedes sigue abundando el amor hacia los otros" (2 Tesalonicenses 1:3). Gracias mi amado Padre por tu sabiduría siempre en mí, la gloria es tuya en la eternidad y desde el comienzo de tu maravillosa creación, obra de tus manos soy, "porque todas las cosas proceden de Él, y existen por Él y para Él. ¡A Él sea la gloria por siempre! Amén" (Romanos 11:36).

\section{Referências}

ANDRADE, Jose Alonso; LEGUIZAMO, Darío Geraldo; VERGARA, Adriana Isabel. 
Educación para la resistencia, una aproximación desde la complejidad. Revista Kavilando, v. 10, n. 2, p. 495-508, 2018.

CARABALlO, Maritza; RODRÍGUEZ, Milagros Elena. Perspectivas complejas y antropoéticas de la Educación Inclusiva Ecosófica. Polyphōnia, Santiago, v. 3, n. 2, p. 117-133, 2019.

DUSSEL, Enrique. 1492: El encubrimiento del Otro. Hacia el origen del mito de la modernidad. Madrid: Nueva Utopía, 1992.

FALS, Orlando. Una sociología sentipensante para América Latina. Ciudad de México: Siglo XXI Editores; Buenos Aires: CLACSO, 2015.

GALILEO, Galilei. II Saggiatore. Roma: Opere VI, 1623.

GONZÁLEZ, Juan Miguel. Por una escuela solidaria y transdisciplinar: conocimientos, valores y sentimientos de comunidad, ética y ciudadanía planetaria. En: PINHO, María José (Ed.). Educação transdisciplinar: escolas criativas e transformadoras. Palmas: EdUFT, 2020, p.47-61.

GONZÁLEZ, Juan Miguel. Tiempo-espacio en el Aula Mente Social. Revista CONCIENCIA, La Paz, v. 3, n. 1, p. 9-16, jul. 2015.

GUATTARI, Felix. Las tres ecologías. Madrid: Pre-Textos, 1996.

MAGAÑA, Luis Fernando. Matemática maya: las fascinantes, rápidas y divertidas Matemáticas de los mayas. Ciudad de México: UNAM, 2006.

MALDONADO-TORRES, Nestor. Transdisciplinariedad y Decolonialidad. Quaderna, Marne-la-Vallée, n. 3, p. 1-20, 2015

MANZANARES, José. Transepistemología y ética transcompleja. Implicaciones en la investigación y la ciencia. Serie Diálogos Transcomplejos, Maracay, v. 2, n. 2, p. 41-47, 2016.

MATUL, Daniel. Fibras del corazón. En: MATUL, Daniel; CABRERA, Edgar. (Ed.). La cosmovisión maya. Ciudad de Guatemala: Liga Maya, 1996, p. 130- 197.

MORÍN, Edgar. Los siete saberes necesarios para la educación del futuro. UNESCO: Francia, 1999.

NERUDA, Pablo. Cien sonetos de amor. Buenos Aires: Editorial Losada, 1959.

NICOLESCU, Basarab. La transdisciplinariedad: manifiesto. Montecarlo: Du Rocher, 1996.

OCAMPO, Aldo Ariel. Comprensión epistemológica de la educación inclusiva: discusiones analítico-metodológicas. Revista Espaço, Laranjeiras, n. 50, p. 21-43, jul./dez. 2018. 
OCAMPO, Aldo Ariel. Contornos teóricos de la Educación Inclusiva. Boletín REDIPE, v. 8, n. 3, p. 66-95, 2019.

OCAMPO, Aldo Ariel. Pensar-de-otro-modo las coordenadas de justicia en las propuestas de Educación Superior Inclusiva: tensiones analítico-metodológicas. Emerging Trends in Education, Tabasco, v. 3, n. 5, p. 1-44, jul./dic. 2020.

PANIKKAR, Raimón. Diálogo intrarreligioso. En: FLORISTÁN, Cassiano; TAMAYO, Juan José. (Ed.). Conceptos fundamentales del cristianismo. Madrid: Trotta, 1993, p. $1144-1155$.

PANIKKAR, Raimón. El diálogo indispensable: paz entre las religiones. Barcelona: Península, 2003.

PANIKKAR, Raimón. The Intrareligious Dialogue. New York: Paulist Press, 1999.

PERALTA, Tenilly; ZAMBRANO, Darío. La ética en la investigación transcompleja. Serie Diálogos Transcomplejos, Miracay, v. 2, n. 2, p. 48-54, 2016.

PÉREZ, Augusto. Las matemáticas modernas: pedagogía, antropología y política. Entrevista a George Papy. Perfiles Educativos, n. 10, p. 41-46, oct./dic. 1980.

RESTREPO, Eduardo; ROJAS. Alex. Inflexión Decolonial. Popayán: Universidad del Cauca, 2010.

RESTREPO, Gabriel. Seguir los pasos de Orlando Fals Borda: religión, música, mundos de la vida y carnaval. Investigación \& Desarrollo, Barranquilla, v. 24, n. 2, 2016, p. 199239, jul./dic. 2017.

RINCÓN, Oriana; MILLÁN, Keila; RINCÓN, Omar. El asunto decolonial: conceptos y debates. Perspectivas, Zulia, v. 3, n. 5, p. 75-95, ene./jun. 2015.

RODRÍGUEZ, Milagros Elena. Deconstrucción: un transmétodo rizomático transcomplejo en la transmodernidad. Sinergias Educativas, Quevedo, v. 4, n. 2, p. 43 58, jul./dic. $2019 b$.

RODRÍGUEZ, Milagros Elena. El des-ligaje de la biopolítica para el re-ligaje en la Educación Matemática Decolonial Transcompleja. Educação Matemática Debate, Montes Claros, v. 4, n. 10, p. 1-19, 2020c.

RODRÍGUEZ, Milagros Elena. Entramados rizomáticos de los sistemas de numeración Egipcios y Mayas. Durango: Editores Instituto Universitario Anglo Español, 2020e.

RODRÍGUEZ, Milagros Elena. La ecología de los saberes en la Educación Matemática Decolonial Transcompleja. Ciências em Foco, Campinas, v. 13, p.1-18, $2020 \mathrm{f}$.

RODRÍGUEZ, Milagros Elena. La Educación Matemática Decolonial Transcompleja como antropolítica. Utopía y Praxis Latinoamericana, Zulia, v. 25, p. 125-137, 2020 b.

RODRÍGUEZ, Milagros Elena. La inclusión en la Educación Matemática decolonial transcompleja. Polyphōnia, Santiago, v. 4, n. 2, p. 236-253, jul./dic. 2020a. 
RODRÍGUEZ, Milagros Elena. La transepistemología de la metódica transcompleja: legitimación y encuentro de los saberes científicos y soterrados. Praxis Educativa ReDIE, v. 11, n. 20, p. 24-38, mayo/oct. 2019c.

RODRÍGUEZ, Milagros Elena. Las matemáticas del amor y la amistad. Caracas: Editorial El Perro y la Rana, 2018.

RODRÍGUEZ, Milagros Elena. Re-ligar como práctica emergente del pensamiento filosófico transmoderno. Orinoco Pensamiento y Praxis, Caracas, v. 7, n. 11, p. 13-35, nov./dic. 2019a.

RODRÍGUEZ, Milagros Elena. Serendipiando con los procesos mentales de la matemática en la complejidad en sentipensar decolonial. Revista Internacional de Formación de Professores, Itapetininga, v. 5, p. 1-23, $2020 \mathrm{~d}$.

RODRÍGUEZ, Milagros Elena; MIRABAL, Mireya. Ecosofía-antropoética: una recivilización de la humanidad. Telos, Maracaibo, v. 22, n. 2, p. 295-309, 2020.

SCHAVINO, Nancy. Hacia una transepistemología de la investigación. En: TORREALBA, Gustavo Ruiz; VARELA, Sandra Salazar. (Org.). Transperspectivas Epistemológicas, Educación, Ciencia y Tecnología. Maracay: REDIT, 2013, p. 67-78.

SKOVSMOSE, Ole; VALERO, Paola. Rompimiento de la neutralidad política: el compromiso crítico de la Educación Matemática con la democracia. En: VALERO, Paola; SKOVSMOSE, Ole. (Ed.), Educación Matemática Crítica: una visión sociopolítica del aprendizaje y la enseñanza de las Matemáticas. Bogotá: Una Empresa Docente, 2012, p. 1-23.

SORET, Zaida. Epistemología del enfoque integrador transcomplejo. Serie Diálogos Transcomplejos, Maracay, v. 2, n. 2, p. 33-38, 2016.

ZOURABICHVILI, Francois. El vocabulario Deleuze. Buenos Aires: Editorial Atuel, 2007. 